\title{
National Climate Observing System of Switzerland (GCOS Switzerland)
}

\author{
G. Seiz and N. Foppa \\ Swiss GCOS Office, Federal Office of Meteorology and Climatology MeteoSwiss, Switzerland
}

Received: 26 December 2010 - Accepted: 26 March 2011 - Published: 12 May 2011

\begin{abstract}
In recent decades, the global observation of climate and climate change has become increasingly important. The Global Climate Observing System (GCOS) established in 1992 addresses the entire climate system including physical, chemical and biological properties of atmosphere, ocean and land surface. This paper describes the GCOS implementation in Switzerland and highlights some major achievements over the last few years. The Swiss GCOS Office was established at the Federal Office of Meteorology and Climatology MeteoSwiss in February 2006, to coordinate all climate-relevant measurements in Switzerland. The first-ever inventory of the country's long-term climatological data series and international data centres, including an assessment of their future prospects, was compiled in 2007. The National Climate Observing System of Switzerland (GCOS Switzerland) includes long-term climatological data series in the atmosphere and terrestrial domains, international data and calibration centres, satellite-based products and support of climate observations in developing countries. A major milestone in the surface-based atmospheric observations was the definition of the Swiss National Basic Climatological Network (NBCN), consisting of 29 stations of greatest climatological importance. The NBCN was further densified for precipitation with 46 additional daily precipitation stations (NBCN-P). Analysis of the homogenized timeseries of the average temperature in Switzerland shows a total warming of $+1.6^{\circ} \mathrm{C}$ from 1864 to 2010 . In the terrestrial domain, substantial advances were made in all three subdomains hydrosphere, cryosphere and biosphere. As example for the use of satellite data within GCOS Switzerland, the 10-yr MODIS monthly mean cloud fraction climatology over Switzerland from March 2000 to February 2010 is presented, which illustrates the differences in cloud cover between mountainous regions and flatland regions in winter, as well as the north-south gradient in cloud cover over Switzerland in summer.
\end{abstract}

\section{Introduction}

In recent decades - especially following the adoption of the Climate Convention in 1992 - the demand for observations of climate and climate change has steadily increased. For scientific conclusions on climate change, the attribution of anthropogenic influences and future climate scenarios, long-term, high-quality data series are essential. The recently published Fourth Assessment Report of the Intergovernmental Panel on Climate Change (IPCC, 2007) summarizes the current state of knowledge on climate change and its global impacts. For Switzerland, the regional impacts have been analyzed in a recent report by the Swiss Advisory Body on Climate Change (OcCC, 2007). According to the OcCC report, Switzerland

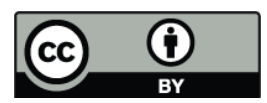

Correspondence to: G. Seiz (gabriela.seiz@meteoswiss.ch) will face autumn, winter and spring temperatures to increase by around $2{ }^{\circ} \mathrm{C}$ and summer temperatures by almost $3{ }^{\circ} \mathrm{C}$ by 2050 compared to 1990 . Precipitation levels are projected to rise by about $10 \%$ in winter and to fall by about $20 \%$ in summer. In addition, the frequency of extreme precipitation events is expected to increase, especially in winter. Climate change scenarios for Switzerland, however, are quantitatively still very uncertain. Early detection of long-term climate variations is therefore essential for the planning and management of climate change adaptation strategies.

This paper gives an overview about the National Climate Observing System in Switzerland (GCOS Switzerland), covering the atmospheric and terrestrial domains, and including international data and calibration centres in Switzerland, the role of satellite data within GCOS Switzerland and the support of climate observations abroad. Finally, an outlook is given on the future strategy of GCOS Switzerland. 


\section{Global Climate Observing System (GCOS)}

\subsection{GCOS overview}

The Global Climate Observing System (GCOS) was established in 1992, parallel to the establishment of the UN Framework Convention on Climate Change (UNFCCC). The aims and requirements of systematic observation are specified in Article 4 and 5 of the UNFCCC and in Article 10 of the subsequent Kyoto Protocol. GCOS is designed to ensure that the observations and information needed to address climate-related issues are obtained and made available to all potential users. GCOS is co-sponsored by the World Meteorological Organization (WMO), the Intergovernmental Oceanographic Commission of UNESCO, the UN Environment Programme (UNEP) and the International Council for Science (ICSU). Building on existing networks and systems, GCOS encompasses the total climate system including observations of physical, chemical and biological properties of the atmosphere, the ocean and the land surface. Within GCOS, a set of so-called Essential Climate Variables (ECV) has been defined, subdivided into atmospheric, oceanic and terrestrial domain (WMO, 2003). The implementation of GCOS is based on the Second Adequacy Report (WMO, 2003) and the Implementation Plan (WMO, 2004). The GCOS Implementation Plan (GIP-04) and its 2010 Update (WMO, 2010a; GIP-10) thereby clearly highlights the role of every country to set up national coordination mechanisms and national plans for the provision of systematic observation of the climate system. Such mechanisms are usually best sustained when a national coordinator (or at least a focal point) is designated and assigned responsibility to coordinate planning and implementation of systematic climate observing systems across the many departments and agencies involved. Regular reporting on climate observations is also an official duty for each Party to the UNFCCC as part of the UNFCCC National Communication (Chapter "Research and Systematic Observation").

\subsection{National GCOS implementation in Switzerland}

Switzerland has a long tradition of climate observation. Temperature and precipitation series of more than $150 \mathrm{yr}$, the world's longest total ozone series and glacier measurements dating back to the end of the 19th century are only a few highlights of Switzerland's contribution to global and regional climate monitoring. The Fourth IPCC Assessment Report makes reference to various papers concerning Swiss climatological time series, e.g. for precipitation (Schmidli and Frei, 2005), radiation (Philipona et al., 2005; Wild et al., 2005), snow (Scherrer et al., 2004), glaciers (Zemp et al., 2005), permafrost (Vonder Mühll et al., 2004) and phenology (Defila and Clot, 2001).

Following the ratification of the Kyoto Protocol by the Swiss Parliament in summer 2003, the national GCOS co- ordination was strengthened at the Federal Office of Meteorology and Climatology MeteoSwiss. On 1 February 2006, the Swiss GCOS Office was established, building on the former GCOS Focal Point at MeteoSwiss. The Swiss GCOS Office is responsible for coordinating climatological observations carried out in Switzerland by federal offices, research institutes and universities. Once a year, a so-called "National Swiss GCOS Roundtable" is organized to foster the information exchange between the different partners and to guarantee a coherent strategy. The coordination also includes longterm planning to ensure continuous and representative observations, e.g. by identifying the risk of discontinuity ahead of time and engaging in remedial action. As far as possible, new measurement techniques are also considered in the integrated observation system. In addition, the Swiss GCOS Office identifies resource-related problems affecting the operation of international data and calibration centres in Switzerland and provides financial and technological support for selected observations abroad.

\section{National Climate Observing System (GCOS Switzerland)}

In 2006, the Swiss GCOS Office and ProClim (i.e. the Forum for Climate and Global Change of the Swiss Academy of Sciences SCNAT) performed a survey among Swiss universities, research institutes and federal offices with the aim of documenting climatological series and identifying risks to their continuation. The criteria were defined on the basis of similar studies for the selection of climatological stations (WMO, 1997). The main criteria specified were that a series should: (a) cover a period of more than $50 \mathrm{yr}$, (b) be longer than comparable series abroad, or (c) concern recently introduced climate variables or observation methods. The secondary criteria included participation in international agreements or data centres, geographical representativeness, data quality and availability of metadata. Respondents were also asked to indicate their requirements for funding in order to ensure continued operation of stations. Based on the survey results, a report about the National Climate Observing System (GCOS Switzerland) has been completed (Seiz and Foppa, 2007). The report is the first inventory of Switzerland's longterm climatological data series and international data centres, including an assessment of their future prospects. The inventory was compiled in cooperation with ProClim and the responsible federal offices, research institutes and universities advised by a steering committee consisting of scientists and policymakers.

Based on the report, the Swiss Federal Council has agreed in June 2008 on a long-term financial contribution to GCOS Switzerland, starting from 2010. This financial contribution will cover the operation costs of several long-term climatological data series of carbon dioxide, freeze dates of lakes, snow water equivalent, glaciers, permafrost and 
(a)

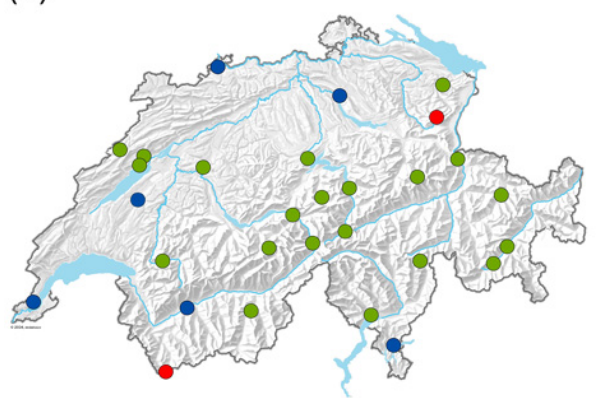

(b)

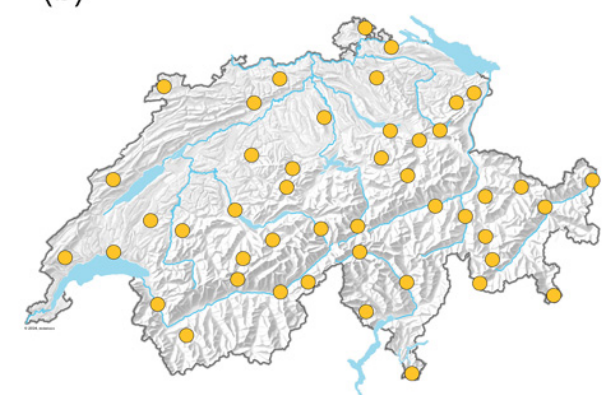

Figure 1. Swiss National Basic Climatological Network (NBCN). (a) 29 NBCN stations; 2 stations also belong to the GCOS Surface Network GSN (red) and 8 to the Regional Basic Climatological Network RBCN (red + blue). (b) additional 46 precipitation stations which complement the NBCN stations to the densified network for precipitation (NBCN-P).

Table 1. Essential climate variables of the atmospheric domain, together with additional variables of relevance for Switzerland (in italics), which are part of GCOS Switzerland.

\begin{tabular}{ll}
\hline Surface & $\begin{array}{l}\text { Air temperature, Precipitation, Air pressure, } \\
\text { Surface radiation budget, Wind speed and di- } \\
\text { rection, Water vapour }\end{array}$ \\
\hline Upper Air & $\begin{array}{l}\text { Earth radiation budget (including solar irradi- } \\
\text { ance), Upper air temperature, Wind speed and } \\
\text { direction, Water vapour, Cloud properties }\end{array}$ \\
\hline Composition & $\begin{array}{l}\text { Carbon dioxide, Methane, Ozone, Other long- } \\
\text { lived greenhouse gases, Aerosol properties, } \\
\text { Pollen }\end{array}$
\end{tabular}

phenology, and of two international data centres in Switzerland (World Glacier Monitoring Service WGMS, palaeohistoric database Euro-Climhist), whose future were identified to be uncertain in the inventory report.

\subsection{Atmospheric domain}

The most important systematic observations of the atmospheric domain in Switzerland concern the surface, upper air and composition (Table 1). Pollen is not listed as ECV in the GCOS Second Adequacy Report, but its measurement has a long tradition in Switzerland and consequently, its series are an important part of the Swiss climate observing system.

In the following, some examples from the surface, upper air and atmospheric composition observations are given. The systematic measurements of surface-based atmospheric variables extend as far back as December 1863, when Switzerland's first nationwide meteorological observation network came into operation. At many of the sites chosen in 1863, stations are still in operation today. In the NORM90 project (Begert et al., 2003, 2005), for each of Switzerland's twelve major climate regions, a station was selected where measure- ment data have been collected since at least 1900. These long time series were analyzed for artificial discontinuities and trends caused, for example, by station relocation, change of instrumentation and calibrations, and homogenized (Begert et al., 2005). In order to increase the density of stations, particularly in the Central Alpine region characterized by large differences in altitude, 16 additional stations were selected with time series from at least 1900 (exception: Jungfraujoch only from 1930). These stations of the greatest climatological importance (28 in all) have recently been designated as the Swiss National Basic Climatological Network (NBCN) (Begert et al., 2007). Two NBCN stations are also GCOS Surface Network (GSN) stations - Säntis and Grand St. Bernard. Seven NBCN stations (Säntis, Grand St. Bernard, Geneva, Sion, Basel, Zurich and Lugano) belong to the WMO Regional Basic Climatological Network (RBCN). Additionally, the aerological station Payerne, as GCOS Upper Air Network (GUAN) station, has been added to the NBCN selection, leading to a total of $29 \mathrm{NBCN}$ stations (Fig. 1a). For precipitation, the Swiss NBCN stations are complemented by 46 precipitation stations (with daily measurements) - selected on the basis of a cluster analysis to densify the Swiss National Basic Climatological Network for Precipitation (NBCN-P) (Begert, 2008) (Fig. 1b). The long time series of precipitation are particularly valuable for assessing the effects of climate change on the water cycle, glacier mass balance and the frequency of flooding events.

Long-term temperature series are crucial for the observation, analysis and quantification of climate change. The deviation of the annual mean temperature in Switzerland 18642010 from the multiyear average (norm 1961-1990), based on 12 stations (Begert et al., 2005), offers a striking example of climate change (Fig. 2). The linear trend between 1864 and 2010 is $+1.1^{\circ} \mathrm{C}$ per $100 \mathrm{yr}\left(+0.1^{\circ} \mathrm{C}\right.$ per $\left.10 \mathrm{yr}\right)$, yielding a total warming of $+1.6^{\circ} \mathrm{C}$ from 1864 to 2010 . Worldwide, the global linear trend for the same time period over land is $+0.6^{\circ} \mathrm{C}$ per $100 \mathrm{yr}$, yielding a total warming of $+0.9^{\circ} \mathrm{C}$ from 1864 to 2010. 


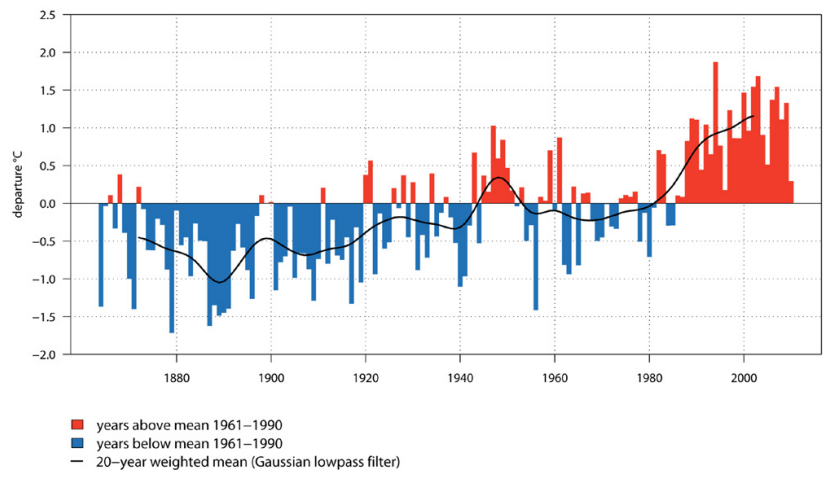

Figure 2. Deviation of the annual mean temperature in Switzerland 1864-2010 from the multiyear average (norm 1961-1990).

Since January 2008 the Payerne aerological station is part of the GCOS Upper Air Network (GUAN), meeting higher quality requirements for long-term monitoring of the climate (WMO, 2010b). Moreover, following a recommendation by the meeting on the implementation of the GCOS Reference Upper Air Network (GRUAN) in Lindenberg (Germany) in February 2008, Payerne has been invited to become part of the initial set of 15 sites forming the GRUAN (WMO, 2009).

Switzerland contributes substantially to the WMO Global Atmosphere Watch (GAW) programme, with longterm observations of radiation (Payerne, Jungfraujoch, Davos, Locarno-Monti), ozone (Arosa, Payerne), aerosols (Jungfraujoch), greenhouse gases (Jungfraujoch, Dübendorf) and air pollutants (Payerne, Jungfraujoch, Rigi). Ten years after its launch, an evaluation of the Swiss GAW (GAW-CH) programme by three international experts was organized in 2005. The experts concluded that the transition from the consolidation phase to the permanent phase in 2007 requires at least the same level of funding as successful monitoring needs continuous improvement from research and development. They also recommended to launch a Swiss GAW_Plus programme which adds or extends components going beyond the current scope of GAW-CH. In the meantime, these recommendations have been fully implemented in the Swiss GAW_Plus programme 2010-2013.

\subsection{Terrestrial domain}

Switzerland's most important systematic climate observations in the terrestrial domain concern the hydrosphere, cryosphere and biosphere (Table 2). Isotopes and Phenology are not listed as ECVs in the GCOS Second Adequacy Report, but their measurements have a long tradition in Switzerland and consequently, their series are an important part of the Swiss climate observing system.

In the following, some examples from hydrosphere, cryosphere and biosphere observations are given. The longest time series of freeze and thaw dates for lakes in Switzerland is from Lake St. Moritz; starting in 1832 and
Table 2. Essential climate variables of the terrestrial domain, together with additional variables of relevance for Switzerland (in italics), which are part of GCOS Switzerland.

\begin{tabular}{ll}
\hline Hydrosphere & $\begin{array}{l}\text { River discharge, Lake levels, Ground water, } \\
\text { Water use, Isotopes }\end{array}$ \\
\hline Cryosphere & $\begin{array}{l}\text { Snow cover, Glaciers and ice caps, Permafrost } \\
\text { and seasonally-frozen ground }\end{array}$ \\
\hline Biosphere & $\begin{array}{l}\text { Albedo, Land cover, Leaf area index, Photosyn- } \\
\text { thetic activity, Biomass, Fire disturbance, Phe- } \\
\text { nology }\end{array}$ \\
\hline
\end{tabular}

extending without interruption up to present. This dataset is unique for central Europe. It is part of a compilation of lake freeze-up and breakup timeseries (Hendricks Franssen and Scherrer, 2008; Magnuson et al., 2000).

As a thermal subsurface phenomenon, permafrost reacts sensitively to changes in climate such as the rising air temperatures currently observed. Warming or thawing of alpine permafrost can influence the stability of steep mountain slopes and lead to problems with high-mountain infrastructure or natural hazards. Permafrost observations (i.e. borehole temperatures, velocities of permafrost creep) are coordinated by the network PERMOS (Permafrost Monitoring Switzerland), which was established by a number of university-based partner institutes in the 1990's (Vonder Mühll et al., 2004); the PERMOS coordination office is currently located at the University of Zurich. The PERMOS network currently includes 14 borehole sites and 13 kinematics sites. Funding for PERMOS on a sustained level has been arranged by MeteoSwiss, the Federal Office for the Environment (FOEN) and the Swiss Academy of Sciences (SCNAT). PERMOS will contribute systematically and on a long-term to the global network of permafrost (GTN-P) providing valuable information on alpine permafrost.

A changing climate affects forests by altering the length of the vegetation period - affecting the future distribution limits of individual tree species. Under the federal Long-term Forest Ecosystem Research (LWF) project, intensive and wideranging studies have been pursued since 1994 as part of an integrated approach to forest monitoring. At 18 LWF monitoring sites in Switzerland (Fig. 3), (a) external anthropogenic and natural influences (air pollution, climate) are evaluated, (b) changes in important components of the forest ecosystem are assessed, (c) forest health indicators are developed, and (d) comprehensive risk assessments are conducted under various stress scenarios. To this end, numerous site-specific variables are permanently monitored. At the LWF sites, meteorological measurements are carried out automatically according to international standards, with one station located in the stand and a second one in a nearby unstocked area. In addition, stand, vegetation, soil and nutrient data are collected 


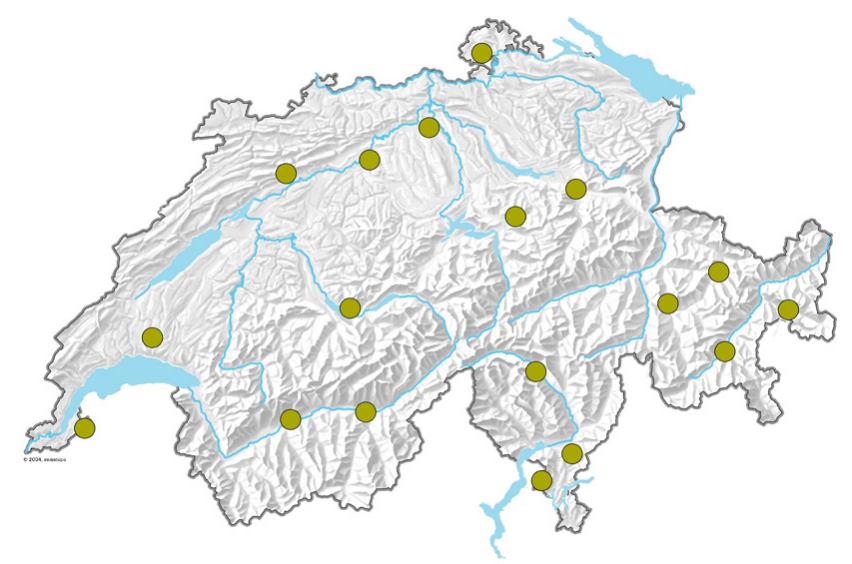

Figure 3. The 18 Long-term Forest Ecosystem Research (LWF) sites.

at varying temporal resolution (hourly to yearly). The aims of the LWF project are in agreement with those of the International Co-operative Programme on Assessment and Monitoring of Air Pollution Effects on Forests (ICP Forests), a programme launched in 1985 under the Convention on Longrange Transboundary Air Pollution (CLRTAP) of the United Nations Economic Commission for Europe (UNECE). The LWF project is also part of the International Long-Term Ecological Research Network (ILTER).

\subsection{International data centres in Switzerland}

To determine state and variability of the climate system, measurements need to be globally standardized. The necessary activities of data collection, storage and redistribution are thereby guaranteed by international data and calibration centres around the world. International data centres have been established for many of the essential climate variables networks and systems. In addition, international calibration centres - with their reference instruments and regular calibration activities - make a vital contribution to the quality of global observation programmes.

In Switzerland, the ETH Zurich maintains the Global Earth Balance Archive (GEBA) database at the ETH Zurich, which provides quality controlled records of monthly mean energy fluxes from 1600 stations worldwide to the climate research community. GEBA incorporates various energy balance components, with a total of 19 different variables. These include, for example, global radiation, short- and long-wave radiation and turbulent heat fluxes. Since 1986, the World Glacier Monitoring Service (WGMS) in Zurich has been coordinating the international collection and publication of glacier data, as well as being responsible for the Global Terrestrial Network for Glaciers (GTN-G) within GCOS/GTOS. The WGMS database currently holds more than 34000 length change measurements from 1725 glaciers and 3000 mass balance observations from 200 glaciers worldwide. The basic funding for WGMS at the University of Zurich is assured since January 2010 by long-term funding support through the Swiss GCOS Office.

The Physical Meteorological Observatory (PMOD) was founded at Davos in 1907 to carry out research in the field of solar radiometry and to study the effects of climate and weather conditions on humans, animals and plants. In 1971, the World Radiation Center (WRC) was established at the PMOD on the recommendation of the World Meteorological Organization (WMO). The World Calibration Centre (WCC) for Surface Ozone, Carbon Monoxide and Methane (WCCEmpa) was established at Empa in 1996 at the request of the WMO. The goal of the WCC is to ensure that measurements carried out at different GAW stations are fully traceable to the designated reference. The GAW Quality Assurance/Scientific Activity Centre (QA/SAC Switzerland) was established at Empa in 2000 and is one of four such facilities worldwide.

Euro-Climhist is a database developed at the Institute of History at the University of Bern, including records of early instrumental measurements, daily to seasonal weather reports and observations on lake and river freezing, snow cover, phenology and the impacts of natural disasters, as well as reports on perceptions of weather. The database is a valuable resource for analysis of the climate history of Switzerland (from the late 15th to the early 19th century) and Europe with a focus upon the Medieval Period. Altogether the database currently holds more than 1.2 million records, of which 620000 are available in digital form. The continuation of Euro-Climhist at the University of Bern is assured since July 2010 by long-term funding support through the Swiss GCOS Office.

\section{The role of satellite data within GCOS Switzerland}

Satellite observations are essential to obtain observations of the climate system from a near-global perspective and to compare the behaviour of different parts of the globe. So, a detailed global climate record for the future critically depends upon a major satellite component within GCOS. Therefore, a report about the systematic observation requirements for satellite-based products for climate has been compiled by the WMO GCOS Secretariat in 2006 as a supplement to GCOS Implementation Plan (GIP-SS; WMO, 2006). To emphasize the role of space agencies in the implementation of GCOS, the UNFCCC Subsidiary Body on Science and Technological Advice (SBSTA-25 in 2006) invited the Parties that support space agencies to enable these agencies to implement, to the extent possible, the actions identified in the Committee on Earth Observation Satellites (CEOS) report (CEOS, 2006) and to continue responding in a coordinated manner through CEOS to the efforts to meet these needs. 

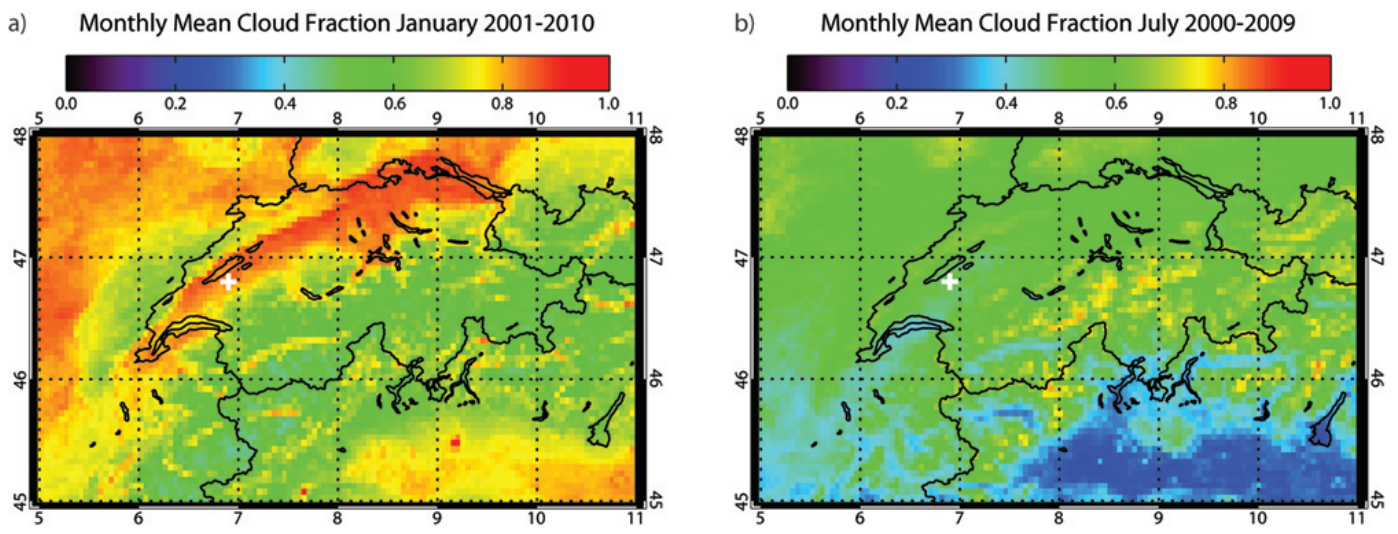

Figure 4. 10-yr monthly mean cloud fraction from MODIS (Terra), at $0.05^{\circ}$ resolution, derived from MOD35 product. (a) January $2001-$ 2010, (b) July 2000-2009.

Switzerland is member of the European Space Agency (ESA) and the European Organisation for the Exploitation of Meteorological Satellites (EUMETSAT). ESA, focused on research and development projects, as well as EUMETSAT, more orientated towards pre-operational and operational projects, have activities in the field of climate monitoring. As high-quality surface and in-situ observations remain of central importance for calibration and validation of satellite data, Switzerland with its many unique observation systems and climate records can play an important role in advancing the integration of satellite data into fundamental climate data records. The Swiss GCOS Office is fostering the exploitation of new measurement techniques, in particular from satellites, within GCOS Switzerland (Seiz et al., 2009, 2011).

As an example for the potential of satellite data for climatological analysis over Switzerland, the 10-yr cloud climatology derived from the MODerate resolution Imaging Spectroradiometer (MODIS) data is presented. MODIS onboard Terra was launched in late 1999 with data stream beginning in late February 2000, followed by MODIS onboard Aqua in May 2002. MODIS features spectral and spatial resolution in key atmospheric bands in order to expand the capability to globally retrieve cloud properties. The MODIS atmosphere products are archived into two categories (Platnick et al., 2003): pixel-level retrievals (Level-2 products) and global gridded statistics at a resolution of $1^{\circ}$ (Level-3 products). The Level-2 MODIS Cloud Mask product (MOD35) is a daily, global product generated at $1 \mathrm{~km}$ spatial resolution. The Level-3 Atmosphere Products (e.g. MOD08) contain statistical datasets from the Level-2 products, summarized over a $1^{\circ}$ by $1^{\circ}$ global equal-angle grid and temporally aggregated into daily, eight-day and monthly files.

To assess the usability of cloud coverage from satellite sensors for Swiss climatological studies, the Level3 parameter "Monthly Cloud Fraction" from MODIS onboard Terra (i.e. MOD08 product) was analysed for the area over the GRUAN station Payerne $\left(6^{\circ} 56^{\prime} \mathrm{E}, 46^{\circ} 48^{\prime} \mathrm{N}\right)$ from March 2000 until December 2008, showing a good agreement in general between the MODIS Terra cloud fraction product (MOD08) and the Synop Payerne data (Seiz et al., 2009). In a follow-up study, the higher resolution MOD35 data were analysed over Switzerland for the $10-\mathrm{yr}$ period March 2000 until February 2010. A daily and monthly cloud fraction was calculated on a $0.05^{\circ} \times 0.05^{\circ}$ grid, based on the MOD35 data. For the calculation, the same methodology as for the operational MOD08 product generation was applied, i.e. assigning a cloud fraction of $100 \%$ to the MOD35 classes "cloudy" and "uncertain/probably cloudy", and a cloud fraction of $0 \%$ to the MOD35 classes "probably clear" and "confident clear". Figure 4 shows the 10 -yr monthly mean cloud fraction for the area of Switzerland for January and July. The seasonal variation in cloud cover between winter and summer is clearly visible. Furthermore, the difference between mountainous regions with lower cloud cover and low altitude regions (Swiss middleland, Northern Italy) with higher cloud cover is well apparent for January. The characteristic north-south gradient is particularly visible in July.

\section{Observations outside Switzerland}

A comprehensive global climate observing system relies on an appropriate spatial distribution of climate-relevant observations. However, as a result of the limited technical and financial resources, the continuation of observations in developing countries is often at risk. It is particularly in these regions that the impacts of climate change are one of the main threats to stability, security and socio-economic development. To respond to this problem, a multilateral financing mechanism, the GCOS Cooperation Mechanism, was launched in 2002. The goal of the mechanism is to improve climate observations primarily in developing and emerging countries. It should also strengthen cooperation between the national GCOS offices and the development 
aid agencies. The observations currently carried out by Swiss institutions abroad cover the following climate variables: ozone (Nairobi, Kenya), trace gases (Assekrem, Algeria; Mt. Kenya, Kenya; Bukit Koto Tabang, Indonesia) and glaciers (30 glaciers worldwide in 9 mountain ranges). Furthermore, the GUAN stations of Dar es Salaam (Tanzania) and Harare (Zimbabwe) have recently been reactivated successfully with the assistance of the Swiss Agency for Development and Cooperation (SDC).

\section{Conclusions and outlook}

Since the establishment of GCOS in 1992, the global climate observing systems have developed and produced promising results. The assessment reports of international climate experts have benefited from the improved information. However, there are still substantial gaps in the measurement networks and many existing observations are threatened, globally as well as in Switzerland. The Swiss GCOS Office at the Federal Office of Meteorology and Climatology MeteoSwiss, established in 2006, is responsible for the national GCOS implementation in Switzerland and seeks to protect the longterm series of essential climate variables and international data and calibration centres in Switzerland that are at risk. Additional aspects deserving special attention within the current and future Swiss GCOS Office activities include metadata, quality assurance and data delivery to the official GCOS international data centres. Furthermore, new measurement technologies on the ground and on satellites will be fostered to help complement the current measurement systems as far as possible. A major challenge for the future will be to ensure continuation of the important historical measurement series as well as to start new measurement series (e.g. soil moisture, soil carbon) for future generations.

Acknowledgements. The Swiss GCOS Office would like to acknowledge all contributors from various federal agencies, research institutes, universities and private companies for their valuable support to prepare this paper. The MODIS MOD35 and MOD08 data were obtained from the "Level 1 and Atmospheric Archive and Distribution System" (LAADS Web).

Edited by: S. Rösner

Reviewed by: two anonymous referees

SC $\mid$ nat $\$ \begin{aligned} & \text { The publication of this article is sponsored } \\ & \text { by the Swiss Academy of Sciences. }\end{aligned}$

\section{References}

Begert M.: Die Repräsentativität der Stationen im Swiss National Basic Climatological Network (Swiss NBCN), Arbeitsberichte der MeteoSchweiz, 217, 40 pp., 2008.

Begert, M., Seiz, G., Schlegel, T., Musa, M., Baudraz, G., and Moesch, M.: Homogenisierung von Klimamessreihen der Schweiz und Bestimmung der Normwerte 1961-1990, Schlussbericht des Projektes NORM90, Veröffentlichungen der MeteoSchweiz, Nr. 67, 170 pp., 2003.

Begert, M., Schlegel, T., and Kirchhofer, W.: Homogeneous temperature and precipitation series of Switzerland from 1864 to 2000, Int. J. Climatol., 25, 65-80, 2005.

Begert, M., Seiz, G., Foppa, N., Schlegel, T., Appenzeller, C., and Müller, G: Die Überführung der klimatologischen Referenzstationen der Schweiz in das Swiss National Basic Climatological Network (Swiss NBCN), Arbeitsberichte der MeteoSchweiz, 215, 43 pp., 2007.

CEOS: Satellite Observation of the Climate System: The Committee on Earth Observation Satellites (CEOS) Response to the Global Climate Observing System (GCOS) Implementation Plan (IP), available at: http://www.ceos.org (last access: 12 May 2011), 2006.

Defila, C. and Clot, B.: Phytophenological trends in Switzerland, Int. J. Biometeorol., 45, 203-207, 2001.

Hendricks Franssen, H.-J. and Scherrer, S.C.: Freezing of lakes on the Swiss Plateau in the period 1901-2006, Int. J. Climatol., 28, 421-433, doi:10.1002/joc.1553, 2008.

IPCC: Climate Change 2007: The Physical Science Basis, in: Contribution of Working Group I to the Fourth Assessment Report of the Intergovernmental Panel on Climate Change, edited by: Solomon, S., Qin, D., Manning, M., Chen, Z., Marquis, M., Averyt, K. B., Tignor, M., and Miller, H. L., Cambridge University Press, Cambridge, United Kingdom and New York, NY, USA, 996 pp., 2007.

Magnuson, J. J., Robertson, D. M., Benson, B. J., Wynne, R. H., Livingstone, D. M., Arai, T., Assel, R. A., Barry, R. G., Card, V., Kuusisto, E., Granin, N. G., Prowse, T. D., Stewart, K. M., and Vuglinski, V. S.: Historical trends in lake and river ice cover in the Northern Hemisphere, Science, 289, 1743-1746, 2000.

OcCC: Klimaänderung und die Schweiz 2050, Erwartete Auswirkungen auf Umwelt, Gesellschaft und Wirtschaft, OcCC/ProClim, Bern, 168 pp., 2007.

Philipona, R., Dürr, B., Ohmura, A., and Ruckstuhl, C.: Anthropogenic greenhouse forcing and strong water vapor feedback increase temperature in Europe, Geophys.. Res. Lett., 32, L19809, doi:10.1029/2005GL023624, 2005.

Platnick, S., King, M. D., Ackerman, S. A., Menzel, W. P., Baum, B. A., Riédi, J. C., and Frey, R. A.: The MODIS Cloud Products: Algorithms and Examples from Terra, IEEE T. Geosci. Remote, 41, 2, 459-473, 2003.

Scherrer, S. C., Appenzeller, C., and Laternser, M.: Trends in Swiss alpine snow days - the role of local and large scale climate variability, Geophys. Res. Lett., 31, L13215, doi:10.1029/2004GL020255, 2004.

Schmidli, J. and Frei, C.: Trends of heavy precipitation and wet and dry spells in Switzerland during the 20th century, Int. J. Climatol., 25, 753-771, 2005. 
Seiz, G. and Foppa, N.: National Climate Observing System (GCOS Switzerland), Publication of MeteoSwiss and ProClim, 92 pp., 2007.

Seiz, G., Foppa, N., and Walterspiel, J.: Use of satellite-based products within the National Climate Observing System (GCOS Switzerland), EUMETSAT Conference Proceedings, p. 55, 2009.

Seiz, G., Foppa, N., Meier, M., and Paul, F.: The Role of Satellite Data Within GCOS Switzerland, Remote Sens., 3(4), 767-780, doi:10.3390/rs3040767, 2011.

Vonder Mühll, D., Nötzli, J., Makowski, K., and Delaloye, R.: Permafrost in Switzerland 2000/2001 and 2001/2002, Glaciological Report (Permafrost) No. 2/3, Glaciological Commission of the Swiss Academy of Sciences, Zurich, 86 pp., 2004.

Wild, M., Gilgen, H., Roesch, A., Ohmura, A., Long, C., Dutton, E., Forgan, B., Kallis, A., Russak, V., and Tsvetkov, A.: From Dimming to Brightening: Decadal Changes in Solar Radiation at Earth's Surface, Science, 308, 847-850, 2005.

WMO: Initial Selection of a GCOS Surface Network, GCOS-34, WMO TD 799, 1997.

WMO: Second Report on the Adequacy of the Global Observing Systems for Climate in Support of the UNFCCC, GCOS-82, WMO TD 1143, 2003.
WMO: Implementation Plan for the Global Observing System for Climate in Support of the UNFCCC, GCOS-92, WMO TD 1219, 2004.

WMO: Systematic Observation Requirements for Satellite-Based Products for Climate, GCOS-107, WMO TD 1338, 2006.

WMO: GRUAN Implementation Plan 2009-2013, GCOS-134, WMO TD 1506, 2009.

WMO: Implementation Plan for the Global Observing System for Climate in Support of the UNFCCC (2010 Update), GCOS-138, WMO TD 1523, 2010a.

WMO: Guide to the GCOS Surface Network (GSN) and GCOS Upper-Air Network (GUAN), GCOS-144, WMO TD 1558, $2010 b$.

Zemp, M., Frauenfelder, R., Haeberli, W., and Hoelzle, M.: Worldwide glacier mass balance measurements: general trends and fi rst results of the extraordinary year 2003 in Central Europe, in: XIII Glaciological Symposium, Shrinkage of the Glaciosphere: Facts and Analyses, St. Petersburg, Russia edited by: Science, R. A. O., Data of Glaciological Studies [Materialy glyatsiologicheskikh issledovaniy], Moscow, Russia, 3-12, 2005. 